\title{
Review
}

\section{Spatial Analysis for Landscape Changes: A Bibliometric Review}

\author{
Maria Danese * (D) and Dario Gioia (D) \\ Institute of Cultural Heritage-National Council of Research, C.da S. Loja, Tito Scalo, 85100 Potenza, Italy; \\ dario.gioia@cnr.it \\ * Correspondence: maria.danese@cnr.it; Tel.: +39-0971427324
}

check for

updates

Citation: Danese, M.; Gioia, D. Spatial Analysis for Landscape Changes: A Bibliometric Review. Appl. Sci. 2021, 11, 10078. https:// doi.org/10.3390/app112110078

Academic Editor: Nadia Giuffrida

Received: 24 September 2021

Accepted: 25 October 2021

Published: 27 October 2021

Publisher's Note: MDPI stays neutral with regard to jurisdictional claims in published maps and institutional affiliations.

Copyright: (c) 2021 by the authors. Licensee MDPI, Basel, Switzerland. This article is an open access article distributed under the terms and conditions of the Creative Commons Attribution (CC BY) license (https:// creativecommons.org/licenses/by/ $4.0 /)$.

\begin{abstract}
The main aim of this study is to analyze from a bibliometric point of view the research trend in spatial analysis for landscape changes using the records published in the Web of Science database in the last twenty years. Several parameters such as documents published per year, sources of documents, number of citations as well as VOSviewer software and GIS are used for the analysis of different metrics such as the number of citations, co-authorship network, and keyword occurrences. Analysis of the number of papers, their keywords, and authorships countries shows the research trend in the specific topics of the spatial analysis for landscape changes and consequently can constitute a benchmark for researchers who approach this research topic.
\end{abstract}

Keywords: spatial analysis; landscape changes; bibliometric mapping; Web of Science

\section{Introduction}

Spatial analysis saw a big improvement in the last few decades thanks to the parallel growth of Information Computer Technologies (ICT), both from the hardware and from the software development point of view. Since then, many research fields have been taking advantage of the spatial analysis discipline. Between these, there are all the studies directly concerned with human- and natural-induced landscape changes. Bibliometric analysis of "hot" research topics is a growing tool for the investigation of emerging disciplines, cooperations, publication impact, and new research trends [1]. In recent years, such an approach has been adopted by several authors to quantitatively delineate the global trend of different research topics or wider disciplines [2-6], highlighting the usefulness of the method to study the past and future direction of research patterns. Moreover, the recent availability of wider databases and innovative software of bibliometric analysis provides new tools for the deeper visual and statistical analysis of temporal and geographic global distribution in research trends [1]. In this work, we carry out a bibliometric analysis of the emerging research topic of the spatial analysis of landscape changes with the aim to investigate the topic's research pattern in the last two decades and to guide researchers to understand future trends.

Landscape changes are very important for the past, present, and future of the Earth and consequently for human life; consequently, as it is shown in this paper, the study of landscape changes through the help of spatial analysis has grown in recent decades and become a hot topic. For this reason, there are many articles belonging to the Ecology, Territorial Planning and Earth Science sectors. Just some examples of the themes afforded in these areas are papers that use spatial analysis for understanding how landscape changes impact species distribution over space and their interaction with environments $[7,8]$, the quantification of natural resources, such as water [9], forests [10-12], and, more in general, of ecosystem services [13,14], and multi-temporal analysis of satellite images and maps as a tool to reconstruct land-use changes and rates of geomorphological processes [15-17]. One of the most effective approaches to investigate natural landscape changes is the geomorphological one, which benefits from recent advances in the development of software and algorithms of digital elevation model (DEM) comparison [18,19], image change detection [20,21], and landscape evolution models [22-25]. Moreover, sustainability is a big topic 
connected with this research line and there are many articles concerning it [26-28], together with analysis connected to climate change [29-31] and pollution quantification [32-34]. However, there are other disciplines such as Archaeology or Historical studies [35-37], or fire analysis [38-40], that are strictly connected to the wider topic of landscape changes.

From what has been said, it is now clear that to consider "spatial analysis for landscape changes" (from here s.a.l.c.) implies covering a very broad area because there are many topics and, at the same time, there are many types of spatial analysis that could be used to investigate these changes, from more traditional methods [41] to more intelligent data analysis [42].

Consequently, the main aim of this paper is to clarify topics, trends, and methods that are connected to the research line of s.a.l.c. through a comprehensive and accurate bibliometric analysis during the last twenty years.

\section{Methodology}

\subsection{Bibliometric Search Engine, Tools, and Software Used for S.A.L.C. Analysis}

To retrieve the scientific literature for this paper, we used the Web of Science database (WoS). Among the most popular bibliographic databases of research papers such as Scopus, WoS, and Google Scholar, we chose WoS because it represents the best compromise among database completeness and cataloguing of higher rank journals [43].

This research was conducted by using the combination of s.a.l.c. keywords, written between the quotation marks, in order to include at the same time all the four keywords and by looking for them inside the title, abstract, and keywords of the scientific paper. Then, the analysis excluded from the research all the WoS categories including the life science disciplines, such as biotechnology, applied microbiology, immunology, oncology, etc.

Regarding the time of publication, two temporal ranges were considered.

The first range considers years from 2001 to 2020, in order to study the general characteristics of scientific literature in the highlighted topic.

The second range considers the same period, from 2001 to 2020, but is divided into four five-year intervals, in order to investigate the long-term literature trends.

To achieve this goal, the following tools were used: first, some tools present inside WoS were used to extract some statistics and graphs; second, an open-source Geographic Information System, QGIS (open source software, downloadable at the site https: / www. qgis.org/it/site/, accessed on 10 October 2021), was used to analyze the geographic distribution of selected works; third, for more specific diagrams, the VOSviewer software was used. It is a free software [44] based on text-mining and it is useful to construct bibliometric maps.

The bibliometric mapping discipline, also called science mapping, recently appeared in order to look for relationships between documents, keywords, or authors [45,46], and with the main aim to investigate the structure and the dynamics of a topic [1,47].

In the literature, other software programs exist for bibliometric mapping, such as SCImat [48] or CiteSpace [49]. Some software reviews are present in [50,51]. We chose VOSviewer for its simplicity, flexibility, and clearness of the results.

\subsection{VOSviewver Diagrams}

Concerning the use of VOSviewer, it offers many useful tools for bibliographic analysis. In this paper, the following diagrams were used:

- The keyword co-occurrence map. It is a distance graph showing the connection between the keywords included in the selected bibliography. If the terms co-occur inside the same phrases, a higher relevance score is assigned to them. Consequently, terms that are linked and near each other in the map are more related. With the co-occurrence map, it is then possible to analyze the main keywords that characterize the state of the art in a domain field. With this type of analysis, VOSviewer returns the graph showing links between key terms, which are also divided into clusters; these clusters are in turn built up on the basis of the co-occurrences of terms inside the paper 
titles. Moreover, the number of occurrences and the total link strength are associated with each term.

- The co-authorship cluster map. In this diagram, the countries where the authors belong are represented as nodes. A bigger node consequently means that more authors come from that country. Lines instead represent the relationship between co-authors coming from different countries.

- The overlay map between keyword co-occurrences and the year when the papers of the studied bibliography were mostly cited. As in the previous maps, nodes and their sizes still represent the number of keyword occurrences, and the lines still represent the strength of co-occurrences between terms, but in this case, the colors represent the citation year.

- Density visualization of the co-occurrences map. This type of graphic facilitates the reading of hot-spots and cold-spots of the keyword with a higher or lower density of co-occurrences [44].

\section{Results}

\subsection{General Quantitative Results}

The first result, obtained from the research in Web of Science, is the quantification of the citations and publications existing in the research field s.a.l.c. A total of 8409 records were found, with a minimum of 86 in 2001 and a maximum of 862 in 2020. Figure 1 shows a consistent increase both in the publication and in the citation number, except for two light drops between years 2002-2003 and 2016-2017. There was also a little decrease in 2020. However, we have to remember that 2020 was an exceptional year because of the COVID-19 pandemic, and this could influence the number and the topic of the worldwide research papers.

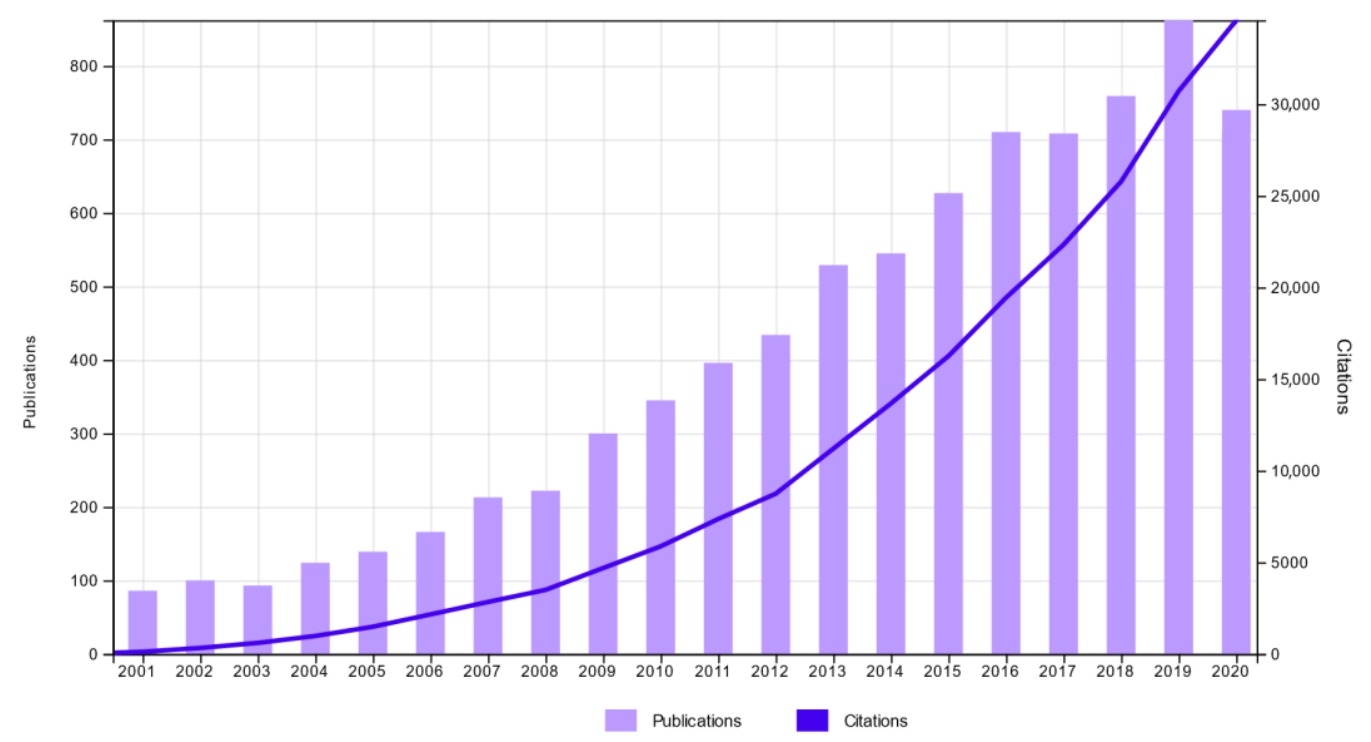

Figure 1. Diagram representing the number of citations and publications reported by Web of Science from 2000 to 2020 .

\subsection{Result Heterogeneity}

In the results obtained by Web of Science, the first aspect that emerges, as expected and explained in the introduction, is the heterogeneity of categories. This aspect is clearly highlighted in Figure 2, where the composition of the first ten categories is visualized in a tree map. Visual inspection of the map highlights that the main categories working in these sectors are environmental disciplines such as Environmental Sciences (in 1st place with 2349 documents, corresponding to $27.6 \%$ of the total data), Ecology (2nd place, 2337, $27.4 \%)$, Multidisciplinary Geosciences (3rd place, 1323, 15.5\%), and Physical Geography 
(4th place, 1236, 14.5\%). Moreover, it is possible to discover a first trend, not directly asked with the query conducted in the Web of Science database. In fact, categories such as Remote Sensing $(873,10.2 \%)$ and the Imaging Science Photographic Technology categories (528, $6.2 \%$ ) are, respectively, classified in 5th and 9th place, suggesting the first delineation of the main techniques and approaches related to the s.a.l.c.
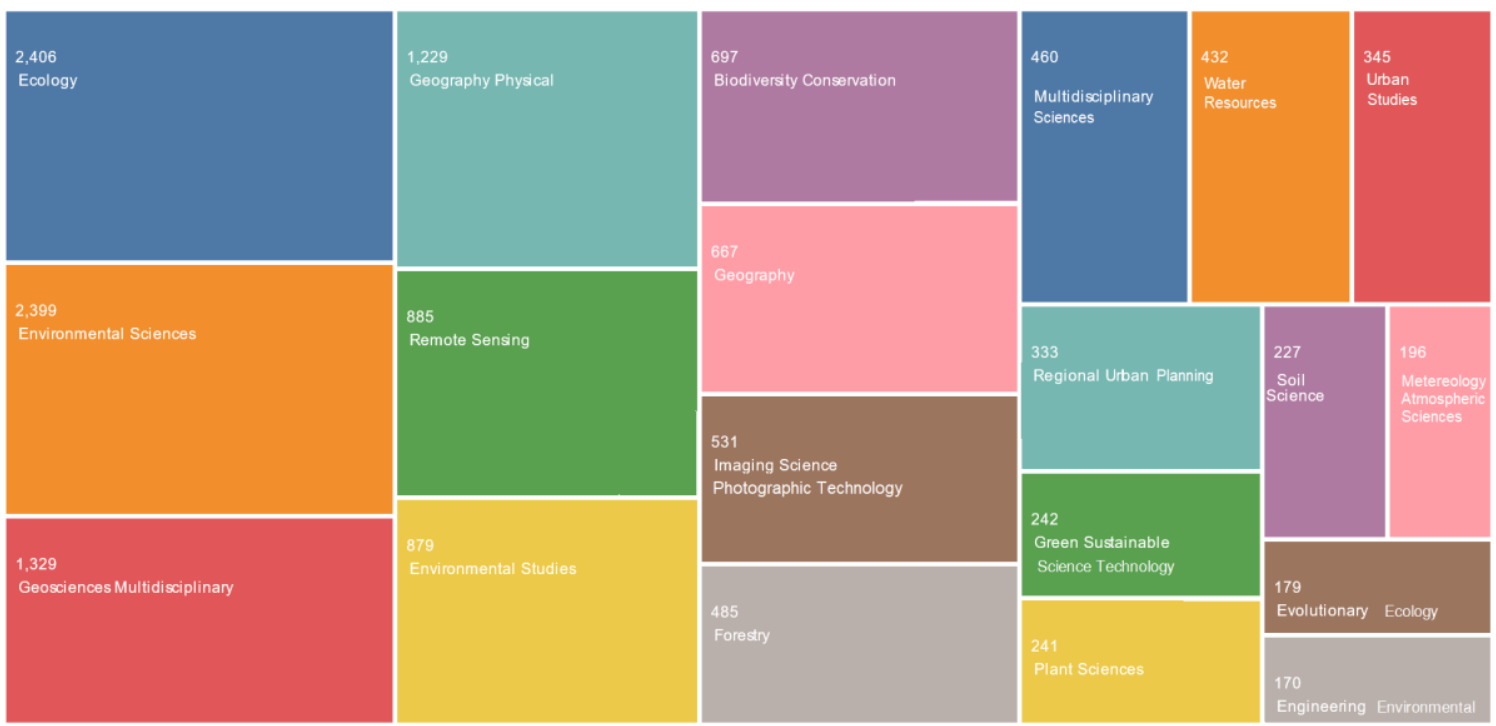

Figure 2. Tree map of the first twenty Web of Science categories where the works about spatial analysis for landscape archaeology are published.

\subsection{Spatial Distribution of S.A.L.C.}

S.a.l.c. literature authorship is spatially distributed all around the world, even if a preliminary analysis of the results indicates a relevant prevalence of European-related papers coming from 129 different countries. Figure 3 shows the frequency of documents found for each country and classified in deciles. The first five countries interested in the research area are the United States of America (with 2765 documents, 32.9\%), China (1205, $14.3 \%)$, Germany $(888,10.0 \%)$, the United Kingdom $(836,10.0 \%)$, and Canada (628, 7.5\%). It is worth noting that the countries that seem not involved in the research topics and present zero articles or very few articles ( 1 or 2 ) are prevalently located in the African continent.

It is also interesting to look at the co-authorship map between countries (Figure 4), and the four main geographical clusters found that are those with the following rank: (1st) the USA, (2nd) China, (3rd) Germany, and (4th) the Netherlands.

\subsection{Co-Occurrence Map of Keywords of the Whole Period}

Concerning the co-occurrence map calculated in the period between 2016 and 2020, four main clusters were found. The prevailing keywords of these clusters are the following (the number of the cluster is just nominal, not ordinal):

- Cluster 1 (Figure 5a, red cluster, a total of 40 items): the keyword with the most occurrences is climate change (1323). Here, secondary terms, besides the word climate (349), express the different aspects of landscape connected to climate change, from vegetation (573) to soil (146) and its erosion (97).

- Cluster 2 (Figure 5a, green cluster, a total of 69 items): the "head" or main terms are biodiversity (769 occurrences), pattern (896), and conservation (778), while minor terms are diversity (428), ecology (330), fragmentation (367), landscape ecology (152), habitat (231), connectivity (190), and landscape connectivity (86). It is interesting to note that the keyword "spatial autocorrelation" (94) was inserted in this cluster instead of the "method" cluster (the Cluster 3), even if, of course, the link with it remains through keywords GIS, land-use change, remote sensing, and, most of all, 
urbanization, which is strictly linked with topics such as the protection or conservation of biodiversity.

- Cluster 3 (Figure 5a, blue cluster, a total of 62 items): here it is possible to highlight two sub-clusters. The first one is prevalently a methodological one, with the main terms GIS (502) and remote sensing (427). The second one is more related to the urban and planning application fields, represented by the main words land-use change (666) and urbanization (431). Terms linked to both are representative of the types of analysis conducted and the instrument used, such as classification (359), the different names of remote sensors, change detection (104), spatial metrics (44), and simulation (165). Moreover, other secondary terms explain where these methods are applied: for urban growth studies (117) and urban expansion (79).

- Cluster 4 (Figure 5a, light green cluster, a total of 40 items): the main word is landscape (1172), while secondary terms are management (560), impact (629), ecosystem services (362), indicators (170), and vulnerability (112). As it is also possible to see from the other minor terms, it is a cluster more oriented to the evaluation of landscape resources, sustainability, and resilience.
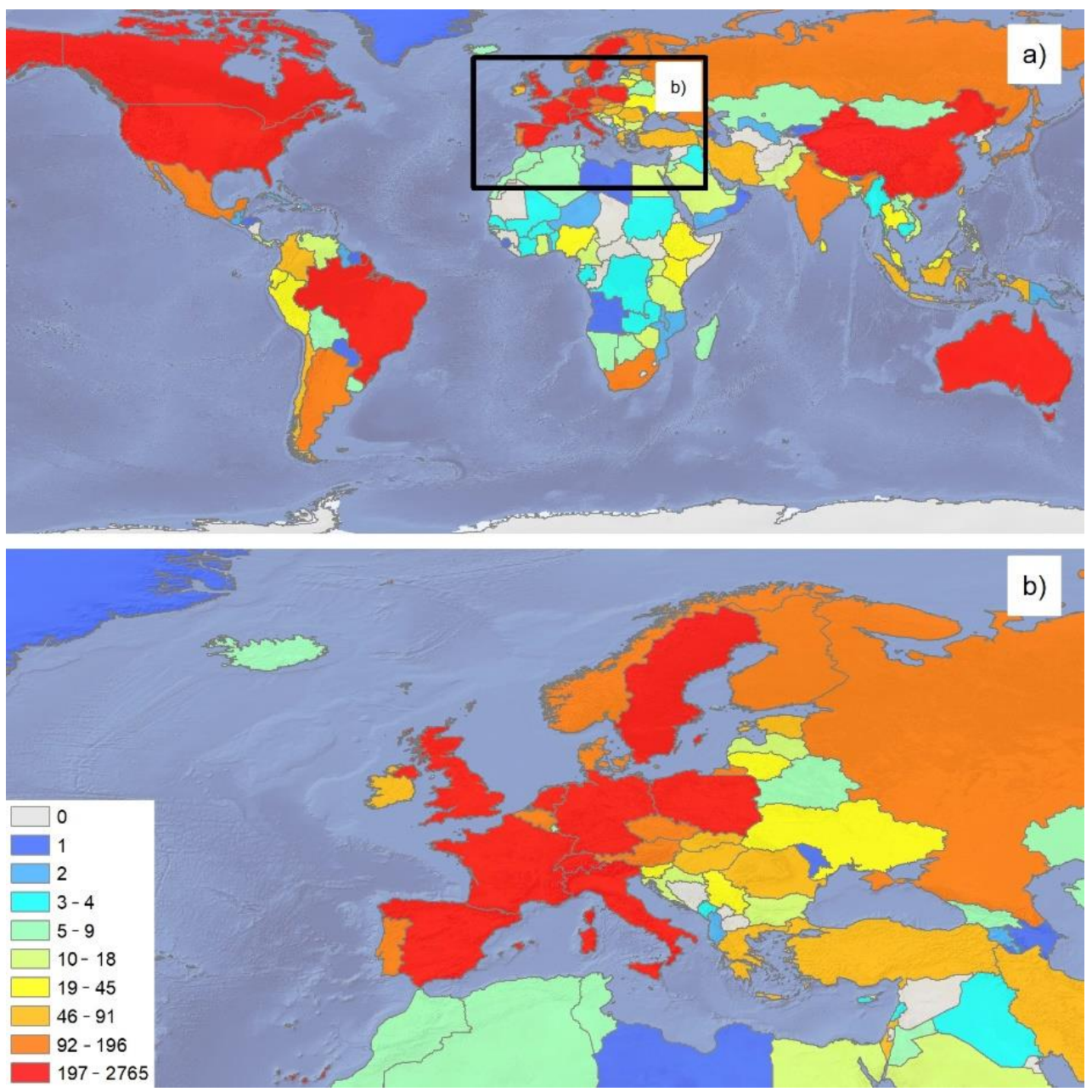

Figure 3. Spatial distribution of the countries of article authorship (a) in the World and (b) in Europe. World background taken from @ naturalearthdata.com. The graph was extracted using QGIS software. 


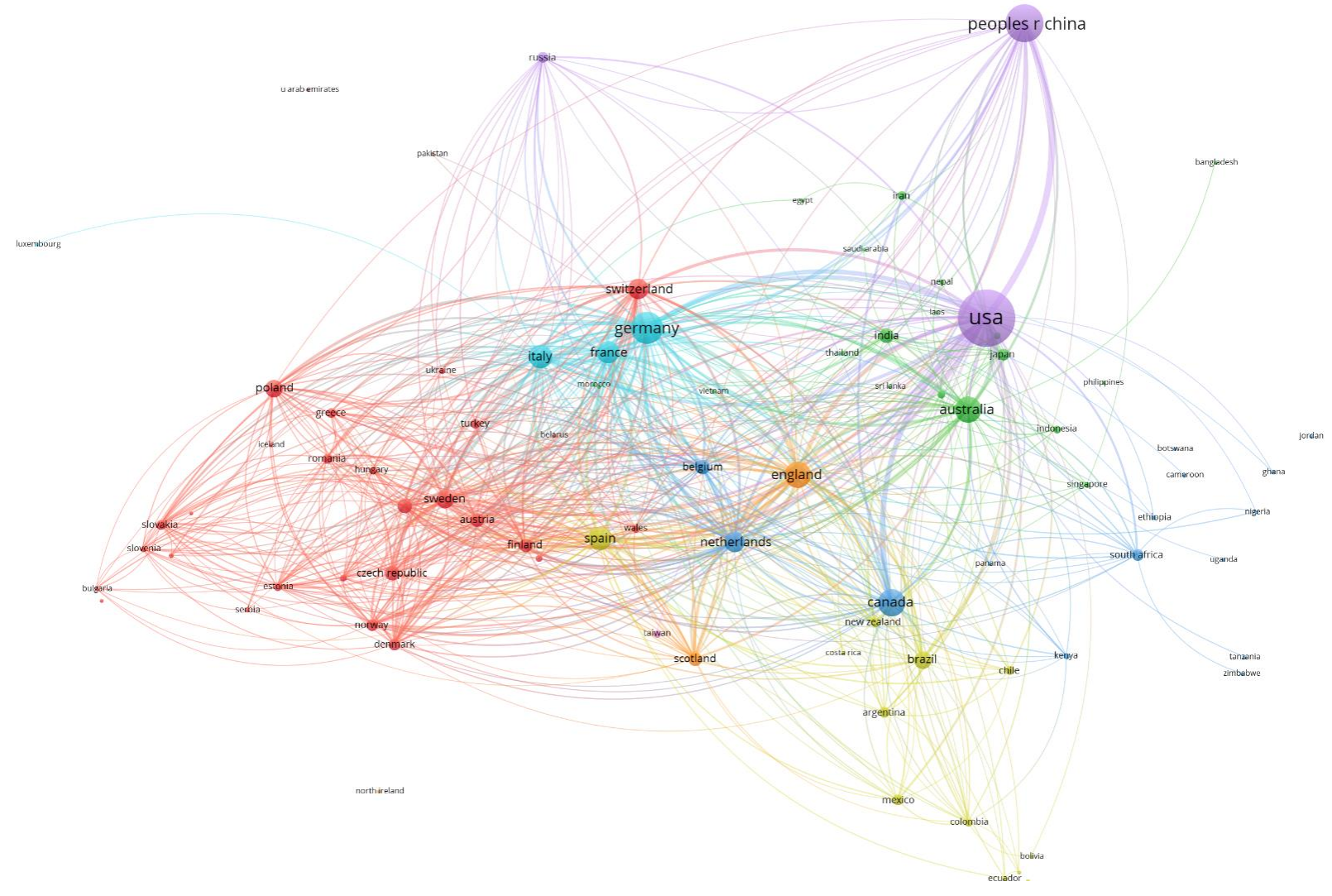

Figure 4. Co-authorship cluster map. Graph obtained by VOSviewer software.

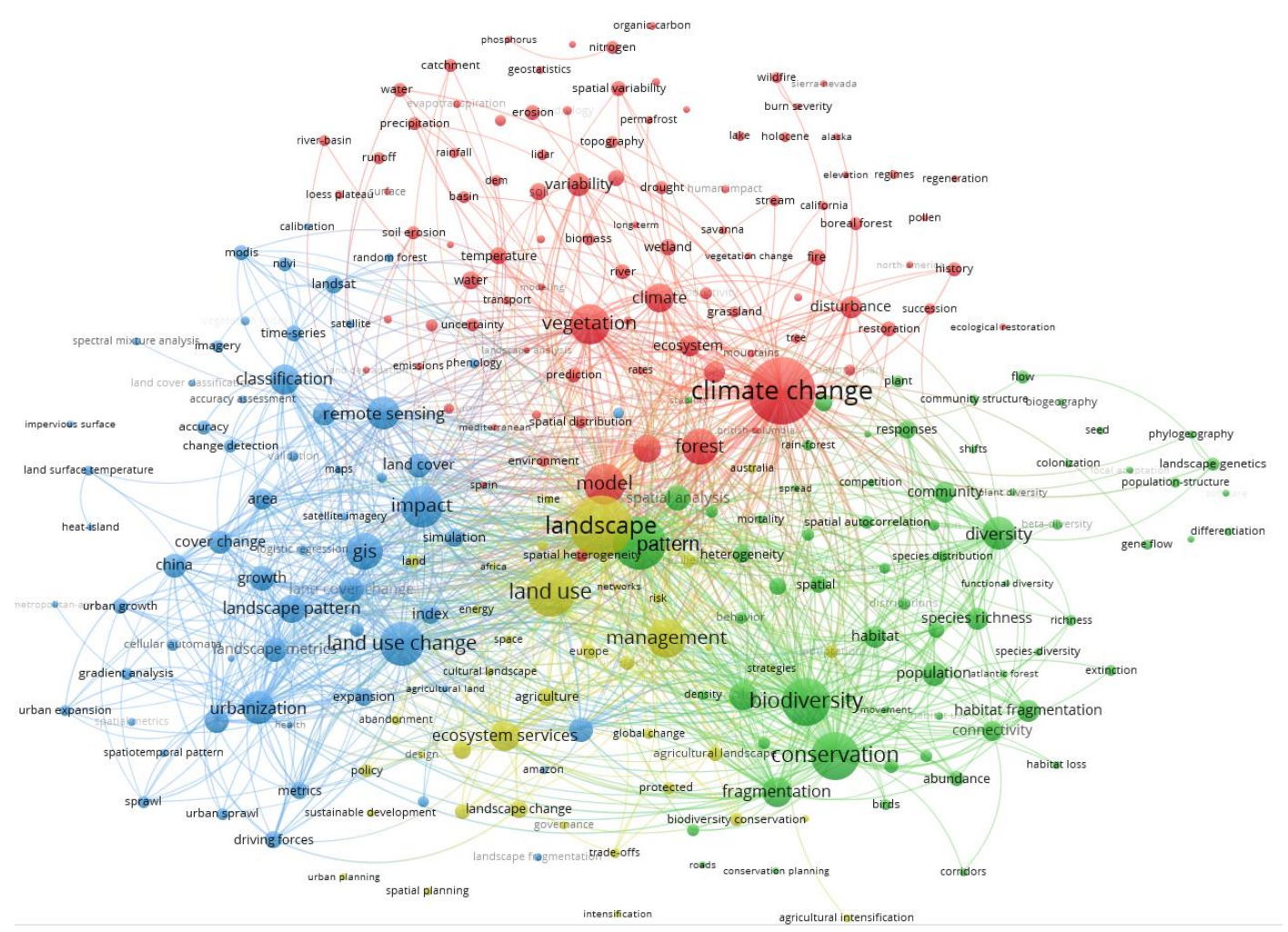

(a)

Figure 5. Cont. 


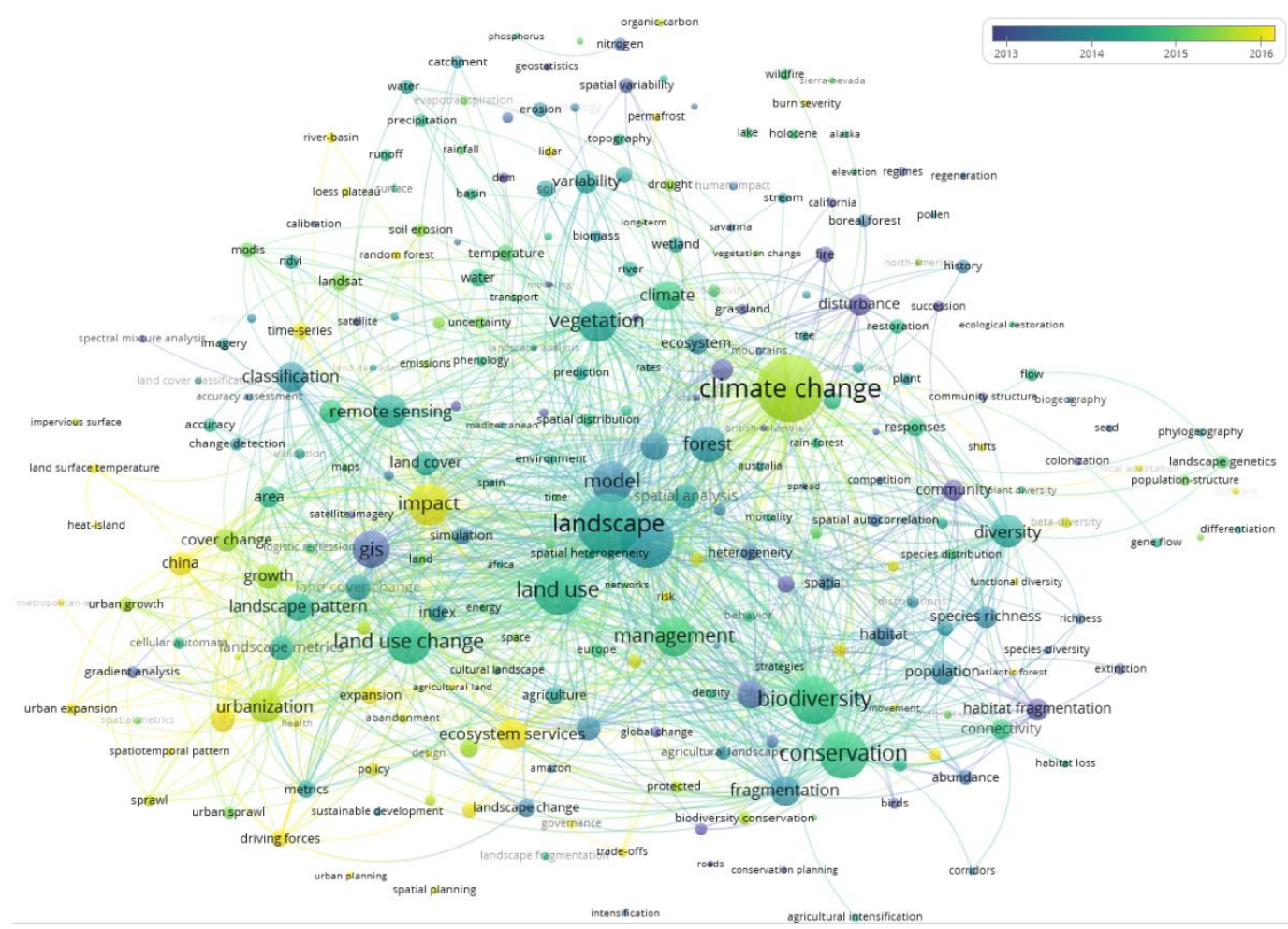

(b)

Figure 5. (a) Co-occurrence map (period: 2001-2020); (b) overlay visualization between key terms and their citation year. Graphs made with VOSviewer software.

By "main word", we meant words with the major frequencies clustered by the software.

Together with the co-occurrence map, we extracted a map where the overlay between terms and the citation year is shown (Figure $5 b$ ): it shows the most cited keywords over the years. In the legend, in particular, the years between 2012 and 2016 are highlighted because this is the temporal range with the largest number of citations. In particular, the most recently cited keywords since 2016 are climate change and ecosystem service, while "older" ones (and actually, they are still consolidated in the literature) are GIS and remote sensing.

\subsection{Density Map for Interval of 5 Years}

In order to investigate the trend in s.a.l.c. research topics on a shorter-term period, we extracted the density map of keywords for four different intervals of 5 years. The interpretation of the maps (Figure 6) could become clearer with the help of data and histograms reported in Figure 7, where occurrence frequencies of the keywords are reported and schematized. Visual inspection of the maps suggests that the two common keywords in the top five list are "landscape" and "pattern". These two words are clearly connected to the main topic of this research. Instead, we can see, for the first two temporal blocks (2001-2005 and 2006-2010), that the other keywords are "model" and "GIS", which are related to the methodological aspects of the research. These two terms, in particular, have a great increase in the second time block (i.e., from 2006 to 2010). Here, the keyword "climate change" also appears. The latter becomes more significant in the third block (2011-2015) and also increases in the 2016-2020 interval. The keyword "climate change" is further reinforced by the last keyword of the top five list, respectively, in 2011-2015, with the terms "biodiversity" and "conservation", and in 2016-2020, with the terms "impact" and, again, "conservation".

Finally, Figure 7 shows the number of occurrences and the related histograms of the keywords already cited in Section 3.4, which considers the most important terms for each 
cluster found in the total period between 2001 and 2020. This is performed to observe the trend of main keywords (in bold, Figure 7) and some of the secondary keywords.

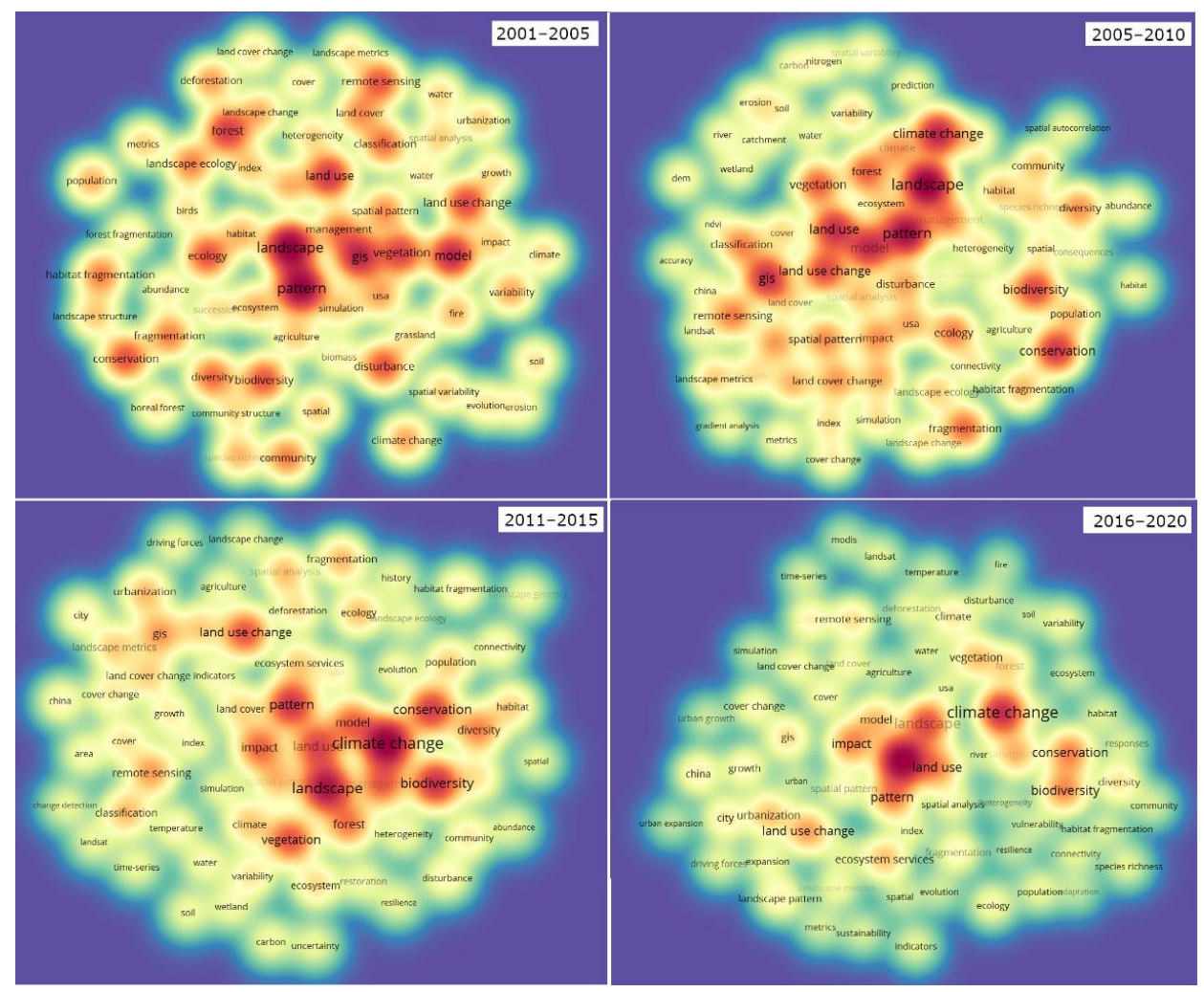

Figure 6. Density map. Obtained with VOSviewer.

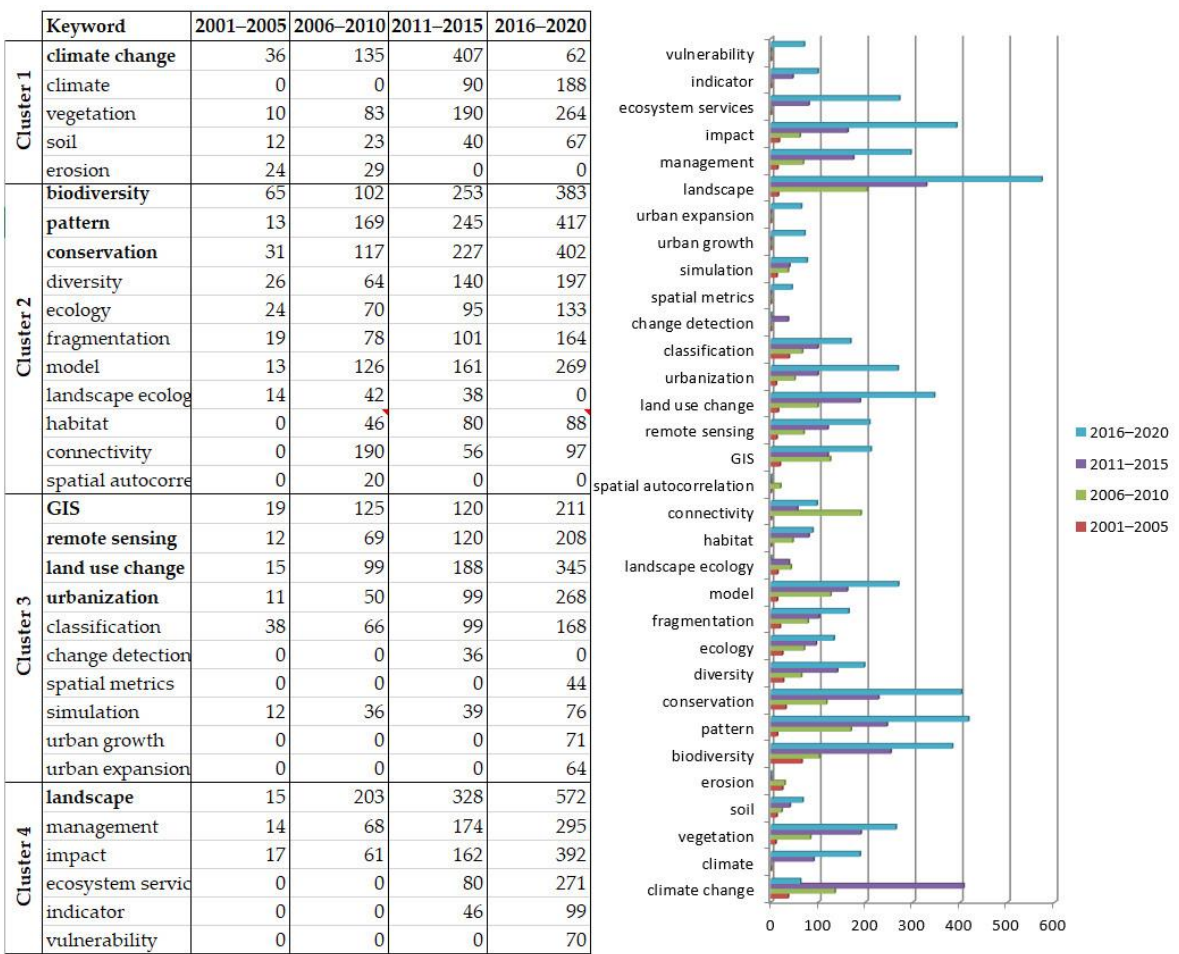

Figure 7. Occurrences and related histograms for the main keywords observed in the 2001-2020 period in order to observe their trend in the four periods. 


\subsection{Types of Spatial Analysis}

Although spatial analysis is a relatively broad term adopted for different and wide research disciplines, an analysis of keywords can be useful to extract information about the main methods and approaches used in s.a.l.c research. To this aim, data were cleaned manually and only keywords concerning methods were left in the analysis. Moreover, keywords with a broader meaning such as "spatial analysis", "remote sensing", or "geospatial analysis" were excluded.

A synoptic scheme of such an analysis is reported in Figure 8, where one can observe the overlay between the co-occurrences map and its overlay with the publication year. Table 1 shows the first 50 keywords, in order of importance for their occurrences: the two top keywords represent, respectively, the traditional method used to analyze a landscape and one of the more innovative methods. In fact, the keyword "classification" (359 occ.) can be correlated to the results of the landscape analysis, whereas the second one (i.e., "simulation", $205 \mathrm{occ}$.) has a strong connection with the approaches adopted for the validation of the results or landscape modeling. Other relevant keywords are the tools used by spatial analysis, such as "indicators" (170 occ.) and "metrics" (156 occ.), or more innovative and specific methods such as "cellular automaton" (113 occ.), "change detection" (104 occ.), "spatial autocorrelation" (103 occ.), "gradient analysis" (84 occ.), "species distribution model" (82 occ.), and "regression" (80 occ.). Among them, "cellular automation" is maybe the most innovative, since has been recently introduced and represents a spatially distributed evolution of artificial intelligence algorithms. Finally, in 10th place, we find the term "(DEM, 72 occ.)", which represents the basic elements of most of the landscape analysis approaches. Additional information about research trends in the s.a.l.c. topic can be inferred from the temporal variation of the keyword occurrences: for example, the prevalence of keywords such as DEM, statistical analysis, data analysis, or regression in the 2012-2013 period (blue tones in Figure 8) seems to suggest research approaches mainly based on visual inspection and basic statistical analysis, while the appearance of peculiar terms in 2016 such as random forest, Markov chain, machine learning, or cellular automata clearly indicates a transition toward the automatic or semi-automatic classification of landscape changes.

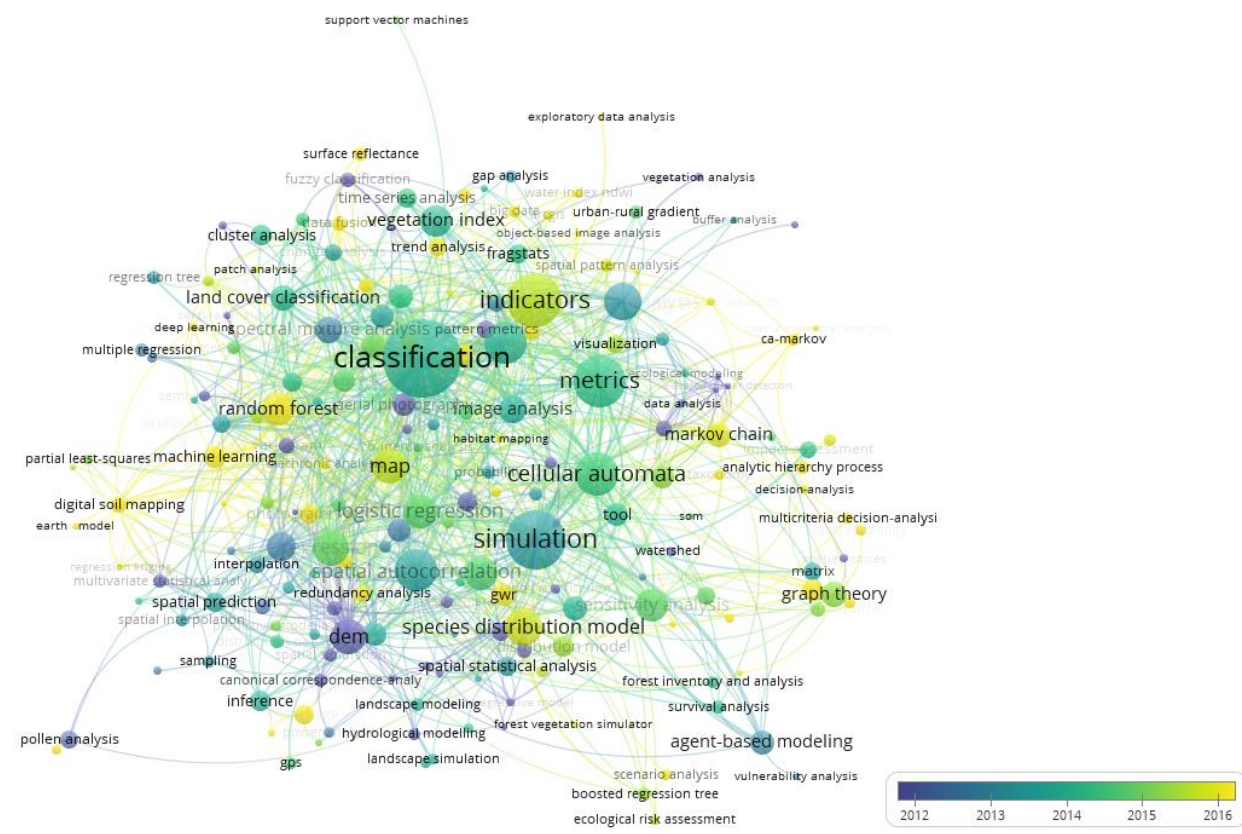

Figure 8. Overlay map for the types of spatial analysis more occurrent in s.a.l.c. research topic. Made with VOSviewer. 
Table 1. First 100 keywords with the highest number of occurrences.

\begin{tabular}{|c|c|c|c|}
\hline Keyword & Occ. $^{1}$ & Keyword & Occ. \\
\hline 01 classification & 359 & 26 agent-based modeling & 34 \\
\hline 02 simulation & 205 & 27 statistical analysis & 34 \\
\hline 03 indicators & 170 & 28 autocorrelation & 33 \\
\hline 04 metrics & 156 & 29 aerial photography & 32 \\
\hline 05 cellular automata & 113 & 30 pattern analysis & 32 \\
\hline 06 change detection & 104 & 31 tool & 32 \\
\hline 07 spatial autocorrelation & 103 & 32 hot spot analysis & 31 \\
\hline 08 gradient analysis & 84 & 33 leaf index & 31 \\
\hline 09 species distribution model & 82 & $\begin{array}{c}34 \text { geographically weighted } \\
\text { regression }\end{array}$ & 30 \\
\hline 10 regression & 80 & 35 machine learning & 29 \\
\hline $11 \mathrm{DEM}$ & 72 & 36 segmentation & 29 \\
\hline 12 map & 71 & 37 network analysis & 28 \\
\hline 13 density & 70 & 38 inference & 27 \\
\hline 14 logistic regression & 67 & 39 cluster analysis & 26 \\
\hline 15 random forest & 65 & 40 distribution model & 26 \\
\hline 16 sensitivity analysis & 62 & 41 intensity & 25 \\
\hline 17 vegetation index & 60 & 42 fractal & 24 \\
\hline 18 geostatistics & 51 & 43 neural network & 23 \\
\hline 19 image analysis & 45 & 44 r-package & 23 \\
\hline 20 spectral mixture analysis & 44 & 45 spatial statistical analysis & 23 \\
\hline 21 land cover classification & 40 & 46 fragstats & 22 \\
\hline 22 graph theory & 37 & 47 photogrammetry & 22 \\
\hline 23 Markov chain & 36 & 48 spatial prediction & 22 \\
\hline 24 object-based classification & 36 & 49 time series analysis & 22 \\
\hline 25 pсa & 35 & 50 swat & 21 \\
\hline
\end{tabular}

${ }^{1}$ Occurrences.

\section{Discussion and Concluding Remarks}

In this paper, a detailed bibliometric investigation of the research trend in spatial analysis for landscape changes using the records published in the Web of Science database in the last twenty years was carried out. Such an approach has been widely used to drive scientists that need to understand the hot topic of a research field or territory (see, for example, [2-4,52-54]).

Our analysis was conducted with the help of three different software packages: the analysis utility offered by WoS, a GIS software (QGIS), and a specific software for bibliometric mapping, VOSviewer. The results highlight that the topic has received increasing attention in the last two decades. As a matter of fact, we observed a constant and exponential increase in the number of papers and citations since 2000. Such an increase can be partly ascribed to: (i) the growing availability of high-resolution DEMs and remote sensing images; (ii) automatic tools or algorithms of landscape classification and the analysis of land-use changes.

Our results also suggest that the research topic is multidisciplinary, ranging from different disciplines such as Environmental Sciences, Earth Sciences, and Ecology, and it is mainly conducted by Chinese, European, and North American research groups. Moreover, on the basis of the statistical analysis of keyword occurrences, it is possible to reconstruct the following main research patterns:

- The literature concerning climate change and the different aspects connected to it, such as the changes in vegetation and soil, grows in particular in the second decade. In spite of this, in the twenty years considered here, we observe the largest pattern in keywords and the highest number of citations;

- $\quad$ The more representative disciplinary areas are urban and territorial planning and ecology. There are two bigger keyword clusters, respectively, headed by land-use changes and biodiversity, conservation and patterns. Additionally, this area shows an increase in occurrences in all the analyzed periods; 
- A third interesting research pattern shows that the two previously cited fields (i.e., urban and territorial planning and ecology) are not considered only as two separated sectors, but there is a correct trial to integrate them with management, impact estimation, and, most of all, with the diffusion of ecosystem services. Such a trend can be mainly observed in recent years;

- Analysis of the frequency distribution of keywords and their temporal trend seems to reveal a modification in the research focus: in particular, the prevalence of keywords such as "Remote Sensing", GIS, and "Land Use" in the early 20th century suggests a methodological approach mainly based on visual inspection or basic GIS analysis of DEMs and satellite images. The spreading of terms such as "classification" or "simulation" and the appearance of keywords such as "cellular automation", "artificial neural network", or "random forest" indicate a clear modification of the research methods, which evolve toward computer-based automation or unsupervised detection of landscape patterns and changes;

- Considering the availability of algorithms and tools useful for fast and accurate analysis of landscape changes in larger areas, we argue that the disciplines/research fields such as geomorphology and the digital reconstruction of historical landscapes could have a relevant growth in the next few years. For example, similar topics can benefit from the growing availability of landscape evolution models $[25,55,56]$ and tools for the visual analysis and reconstruction of historical landscapes $[57,58]$.

To achieve a deeper understanding of the research trend, each map in a wide research field such as s.a.l.c. would request a widening of the analysis and the reading of results in the different clusters and thematic areas identified. This would provide enough material for many other future studies in order to identify an internal state of the art and trends of those subsectors.

Author Contributions: Conceptualization, M.D. and D.G.; methodology, M.D. and D.G.; software, M.D and D.G.; validation, M.D. and D.G.; formal analysis, M.D. and D.G.; investigation, M.D. and D.G.; resources, M.D. and D.G.; data curation, M.D. and D.G.; writing-original draft preparation, M.D. and D.G.; writing — review and editing, M.D. and D.G.; visualization, M.D. and D.G. All authors have read and agreed to the published version of the manuscript.

Funding: This research received no external funding.

Institutional Review Board Statement: Not applicable.

Informed Consent Statement: Not applicable.

Data Availability Statement: All the data used in this paper can be found at the Web of Science search engine (https: / / www.webofscience.com/wos/woscc/basic-search, accessed on 10 October 2021).

Conflicts of Interest: The authors declare no conflict of interest.

\section{References}

1. Noyons, E.C.M.; Moed, H.F.; Luwel, M. Combining mapping and citation analysis for evaluative bibliometric purposes: A bibliometric study. J. Am. Soc. Inf. Sci. 1999, 50, 115-131. [CrossRef]

2. Bezak, N.; Mikoš, M.; Borelli, P.; Alewell, C.; Alvarez, P.; Alexandre, J.; Anache, A.; Baartman, J.; Ballabio, C.; Biddoccu, M.; et al. Soil erosion modelling: A bibliometric analysis. Environ. Res. 2021, 197, 111087. [CrossRef]

3. Su, X.; Li, X.; Kang, Y. A Bibliometric Analysis of Research on Intangible Cultural Heritage Using CiteSpace. SAGE Open 2019, 9, 2158244019840119. [CrossRef]

4. Niu, B.; Yuan, J.; Peng, S.; Zhang, X. Global trends in sediment-related research in earth science during 1992-2011: A bibliometric analysis. Scientometrics 2014, 98, 511-529. [CrossRef]

5. Gariano, S.L.; Guzzetti, F. Landslides in a changing climate. Earth-Sci. Rev. 2016, 162, 227-252. [CrossRef]

6. Reichenbach, P.; Rossi, M.; Malamud, B.D.; Mihir, M.; Guzetti, F. A review of statistically-based landslide susceptibility models. Earth-Sci. Rev. 2018, 180, 60-91. [CrossRef]

7. Frey, S.; Fisher, J.T.; Burton, A.C. Investigating animal activity patterns and temporal niche partitioning using camera-trap data: Challenges and opportunities. Remote Sens. Ecol. Conserv. 2017, 3, 123-132. [CrossRef] 
8. Kay, S.L.; Fischer, J.W.; Monaghan, A.J.; Beasley, J.C.; Boughton, R.; Campbell, T.A.; Cooper, S.M.; Ditchkoff, S.S.; Hartley, S.B.; Kilgo, J.C.; et al. Quantifying drivers of wild pig movement across multiple spatial and temporal scales. Mov. Ecol. 2017, 5, 14. [CrossRef]

9. Lin, L.; Li, M.; Chen, H.; Lai, X.; Zhu, H.; Wang, H. Integrating landscape planning and stream quality management in mountainous watersheds: A targeted ecological planning approach for the characteristic landscapes. Ecol. Indic. 2020, $117,106557$. [CrossRef]

10. Brock, P.M.; Fornace, K.M.; Grigg, M.J.; Anstey, N.M.; William, T.; Cox, J.; Drakeley, C.J.; Ferguson, H.M.; Kao, R.R. Predictive analysis across spatial scales links zoonotic malaria to deforestation. Proc. R. Soc. B Biol. Sci. 2019, 286, 20182351. [CrossRef]

11. Lin, Y.; Hu, X.; Zheng, X.; Hou, X.; Zhang, Z.; Zhou, X.; Qiu, R.; Lin, J. Spatial variations in the relationships between road network and landscape ecological risks in the highest forest coverage region of China. Ecol. Indic. 2019, 96, 392-403. [CrossRef]

12. Zhou, W.Q.; Zhang, S.; Yu, W.J.; Wang, J.; Wang, Q. Effects of Urban Expansion on Forest Loss and Fragmentation in Six Megaregions, China. Remote Sens. 2017, 9, 991. [CrossRef]

13. Garcia-Nieto, A.P.; Geijzendorffer, I.R.; Baro, F.; Roche, P.K.; Bondeau, A.; Cramer, W. Impacts of urbanization around Mediterranean cities: Changes in ecosystem service supply. Ecol. Indic. 2018, 91, 589-606. [CrossRef]

14. Wang, J.; Zhou, W.; Pickett, S.T.A.; Yu, W.; Li, W. A multiscale analysis of urbanization effects on ecosystem services supply in an urban megaregion. Sci. Total Environ. 2019, 662, 824-833. [CrossRef] [PubMed]

15. Gioia, D.; Amodio, A.M.; Maggio, A.; Sabia, C.A. Impact of Land Use Changes on the Erosion Processes of a Degraded Rural Landscape: An Analysis Based on High-Resolution DEMs, Historical Images, and Soil Erosion Models. Land 2021, $10,673$. [CrossRef]

16. Nampak, H.; Pradhan, B.; Rizeei, H.M.; Park, H.J. Assessment of land cover and land use change impact on soil loss in a tropical catchment by using multitemporal SPOT-5 satellite images and Revised Universal Soil Loss Equation model. Land Degrad. Dev. 2018, 29, 3440-3455. [CrossRef]

17. Fortugno, D.; Boix-Fayos, C.; Bombino, G.; Denisi, P.; Quinonero Rubio, J.M.; Tamburino, V.; Zema, D.A. Adjustments in channel morphology due to land-use changes and check dam installation in mountain torrents of Calabria (southern Italy). Earth Surf. Process. Landf. 2017, 42, 2469-2483. [CrossRef]

18. Han, S.H. Thematic map construction of erosion and deposition in rivers using GIS-based DEM comparison technique. J. Korean Soc. Surv. Geod. Photogramm. Cartogr. 2016, 34, 153-159. [CrossRef]

19. Hugenholtz, C.H.; Whitehead, K.; Brown, O.W.; Barchyn, T.E.; Moornam, B.J.; LeClair, A.; Riddell, K.; Hamilton, T. Geomorphological mapping with a small unmanned aircraft system (sUAS): Feature detection and accuracy assessment of a photogrammetrically-derived digital terrain model. Geomorphology 2013, 194, 16-24. [CrossRef]

20. Anders, N.S.; Seijmonsbergen, A.C.; Bouten, W. Geomorphological change detection using object-based feature extraction from multioral lidar data. IEEE Geosci. Remote Sens. Lett. 2013, 10, 1587-1591. [CrossRef]

21. Conforti, M.; Mercuri, M.; Borrelli, L. Morphological changes detection of a large earthflow using archived images, lidar-derived $\mathrm{dtm}$, and uav-based remote sensing. Remote Sens. 2021, 13, 120. [CrossRef]

22. Coulthard, T.J.; van de Wiel, M.J. Modelling long term basin scale sediment connectivity, driven by spatial land use changes. Geomorphology 2017, 277, 265-281. [CrossRef]

23. Ramirez, J.A.; Zischg, A.P.; Schürmann, S.; Zimmerman, M.; Weingartner, R.; Coulthard, T.; Keiler, M. Modeling the geomorphic response to early river engineering works using CAESAR-Lisflood. Anthropocene 2020, 32, 100266. [CrossRef]

24. Gioia, D.; Schiattarella, M. Modeling Short-Term Landscape Modification and Sedimentary Budget Induced by Dam Removal: Insights from LEM Application. Appl. Sci. 2020, 10, 7697. [CrossRef]

25. Gioia, D.; Lazzari, M. Testing the Prediction Ability of LEM-Derived Sedimentary Budget in an Upland Catchment of the Southern Apennines, Italy: A Source to Sink Approach. Water 2019, 11, 991. [CrossRef]

26. Broto, V.C. Energy landscapes and urban trajectories towards sustainability. Energy Policy 2017, 108, 755-764. [CrossRef]

27. Cumming, G.S.; Morrison, T.H.; Hughes, T.P. New Directions for Understanding the Spatial Resilience of Social-Ecological Systems. Ecosystems 2017, 20, 649-664. [CrossRef]

28. Zhou, W.; Pickett, S.T.A.; Cadenasso, M.L. Shifting concepts of urban spatial heterogeneity and their implications for sustainability. Landsc. Ecol. 2017, 32, 15-30. [CrossRef]

29. Ackerly, D.D.; Loarie, S.R.; Cornwell, W.K.; Weiss, S.B.; Hamilton, H.; Branciforte, R.; Kraft, N.J.B. The geography of climate change: Implications for conservation biogeography. Divers. Distrib. 2010, 16, 476-487. [CrossRef]

30. Post, E.; Stenseth, N.C. Climatic variability, plant phenology, and northern ungulates. Ecology 1999, 80, 1322-1339. [CrossRef]

31. Sork, V.L.; Aitken, S.N.; Dyer, R.J.; Eckert, A.J.; Legendre, P.; Neale, D.B. Putting the landscape into the genomics of trees: Approaches for understanding local adaptation and population responses to changing climate. Tree Genet. Genomes 2013, 9, 901-911. [CrossRef]

32. Weng, Q.; Yang, S. Urban Air Pollution Patterns, Land Use, and Thermal Landscape: An Examination of the Linkage Using GIS. Environ. Monit. Assess. 2006, 117, 463-489. [CrossRef]

33. Liu, Y.; Wu, J.; Yu, D. Characterizing spatiotemporal patterns of air pollution in China: A multiscale landscape approach. Ecol. Indic. 2017, 76, 344-356. [CrossRef]

34. Volk, M.; Hirschfeld, J.; Dehnhardt, A.; Schmidt, G.; Bohn, C.; Liersch, S.; Gassman, P.W. Integrated ecological-economic modelling of water pollution abatement management options in the Upper Ems River Basin. Ecol. Econ. 2008, 66, 66-76. [CrossRef] 
35. Kantner, J. The Archaeology of Regions: From Discrete Analytical Toolkit to Ubiquitous Spatial Perspective. J. Archaeol. Res. 2007, 16, 37-81. [CrossRef]

36. Banerjee, R.; Srivastava, P.K. Reconstruction of contested landscape: Detecting land cover transformation hosting cultural heritage sites from Central India using remote sensing. Land Use Policy 2013, 34, 193-203. [CrossRef]

37. Fyfe, R.M. Bronze Age landscape dynamics: Spatially detailed pollen analysis from a ceremonial complex. J. Archaeol. Sci. 2012, 39, 2764-2773. [CrossRef]

38. Conedera, M.; Tinner, W.; Neff, C.; Meurer, M.; Dickens, A.F.; Krebs, P. Reconstructing past fire regimes: Methods, applications, and relevance to fire management and conservation. Quat. Sci. Rev. 2009, 28, 555-576. [CrossRef]

39. Keane, R.E.; Cary, G.J.; Davies, I.D.; Flannigan, M.; Gardner, R.H.; Lavorel, S.; Lenihan, J.M.; Li, C.; Rupp, T. A classification of landscape fire succession models: Spatial simulations of fire and vegetation dynamics. Ecol. Model. 2004, 179, 3-27. [CrossRef]

40. Niklasson, M.; Granstrom, A. Numbers and sizes of fires: Long-term spatially explicit fire history in a Swedish boreal landscape. Ecology 2000, 81, 1484-1499. [CrossRef]

41. Seto, K.C.; Fragkias, M. Quantifying spatiotemporal patterns of urban land-use change in four cities of China with time series landscape metrics. Landsc. Ecol. 2005, 20, 871-888. [CrossRef]

42. Parker, D.C.; Manson, S.; Janssen, M.A.; Hoffmann, M.J.; Deadman, P. Multi-Agent Systems for the Simulation of Land-Use and Land-Cover Change: A Review. Ann. Assoc. Am. Geogr. 2003, 93, 314-337. [CrossRef]

43. Pranckute, R. Web of Science (WoS) and Scopus: The Titans of Bibliographic Information in Today's Academic World. Publications 2021, 9, 12. [CrossRef]

44. van Eck, N.J.; Waltman, L. Software survey: VOSviewer, a computer program for bibliometric mapping. Scientometrics 2010, 84, 523-538. [CrossRef]

45. Small, H. Visualizing science by citation mapping. J. Am. Soc. Inf. Sci. 1999, 50, 799-813. [CrossRef]

46. Morris, S.A.; Van Der Veer Martens, B. Mapping research specialties. Annu. Rev. Inf. Sci. Technol. 2008, 42, 213-295. [CrossRef]

47. Börner, K.; Chen, C.; Boyack, K.W. Visualizing knowledge domains. Annu. Rev. Inf. Sci. Technol. 2003, 37, 179-255. [CrossRef]

48. Cobo, M.J.; López-Herrera, A.G.; Herrera-Viedma, E.; Herrera, F. SciMAT: A new science mapping analysis software tool. J. Am. Soc. Inf. Sci. Technol. 2012, 63, 1609-1630. [CrossRef]

49. Chen, C. CiteSpace II: Detecting and visualizing emerging trends and transient patterns in scientific literature. J. Am. Soc. Inf. Sci. Technol. 2006, 57, 359-377. [CrossRef]

50. Cobo, M.J.; López-Herrera, A.G.; Herrera-Viedma, E.; Herrera, F. Science mapping software tools: Review, analysis, and cooperative study among tools. J. Am. Soc. Inf. Sci. Technol. 2011, 62, 1382-1402. [CrossRef]

51. Moral-Muñoz, J.A.; López-Herrera, A.G.; Herrera-Viedma, E.; Cobo, M.J. Science mapping analysis software tools: A review. In Springer Handbook of Science and Technology Indicators; Springer: Cham, Switzerland, 2019; pp. 159-185.

52. Gizzi, F.T.; Proto, M.; Potenza, M.R. The Basilicata region (Southern Italy): A natural and 'human-built' open-air laboratory for manifold studies. Research trends over the last 24 years (1994-2017). Geomat. Nat. Hazards Risk 2019, 10, 433-464. [CrossRef]

53. Odenwald, S.F. A citation study of earth science projects in citizen science. PLoS ONE 2020, 15, e0235265. [CrossRef] [PubMed]

54. Agapiou, A.; Lysandrou, V. Remote sensing archaeology: Tracking and mapping evolution in European scientific literature from 1999 to 2015. J. Archaeol. Sci. Rep. 2015, 4, 192-200. [CrossRef]

55. Poeppl, R.; Coulthard, T.; Keesstra, S.; Keiler, M. Modeling the impact of dam removal on channel evolution and sediment delivery in a multiple dam setting. Int. J. Sediment Res. 2019, 34, 537-549. [CrossRef]

56. Hancock, G.; Coulthard, T.; Martinez, C.; Kalma, J. An evaluation of landscape evolution models to simulate decadal and centennial scale soil erosion in grassland catchments. J. Hydrol. 2011, 398, 171-183. [CrossRef]

57. Danese, M.; Biscione, M.; Coluzzi, R.; Lasaponara, R.; Murgante, B.; Masini, N. An integrated methodology for medieval landscape reconstruction: The case study of Monte Serico. In Proceedings of the International Conference on Computational Science and Its Applications, Seoul, Korea, 29 June-2 July 2009; Springer: Berlin/Heidelberg, Germany, 2009; pp. 320-340.

58. Roubis, D.; Sogliani, F.; Gabellone, F.; Danese, M.; Gnesi, D. Archaeological Landscapes through GIS (Cost Surface Analysis) and Virtual Reality, A case study on the monastic site of Jure Vetere (Calabria-Italy). In Proceedings of the 36th CAA Conference-On the Road to Reconstructing the Past. Computer Applications and Quantitative Methods in Archaeology, Budapest, Hungary, 2-6 April 2008. 